\title{
Systemic obstacles and possible solutions to crisis management between China and the US
}

\section{Bo $\mathrm{Hu}^{1}$ (1)}

Received: 29 August 2021 / Accepted: 28 October 2021 / Published online: 24 November 2021 (c) The Institute of International and Strategic Studies (IISS), Peking University 2021

\begin{abstract}
As competition between China and the United States intensifies, crisis management is becoming a central issue between the two countries and their militaries. However, though both sides demonstrate strong will to strengthen crisis management, progress has been slow. As to the reason for this, previous academic studies mostly focus on the unit level and officials just engage in finger-pointing. This paper analyzes systemic obstacles to Sino-US crisis management and discusses the significance of these systemic factors for Sino-US crisis management approaches and methods. On this basis, this paper argues that the particularity of Sino-US military competition is unprecedented; the military competitions between other great power dyads in history, such as that between the United States and the Soviet Union, are not comparable. Thus, in the context of general peace among major powers, both China and the US must switch from building mutual confidence and removing mutual distrust to managing and controlling competition trends and surpass the efforts made by the US and the Soviet Union in the past.
\end{abstract}

Keywords China-US relations · Power competition · Crisis management · Western Pacific $\cdot$ Sea power

Improving crisis management may be the only area of consensus between China and the United States (US) regarding strategic security. Since 2020, increasing ChinaUS competition, especially in the Taiwan Strait and the South China Sea, has led both states to become aware of the risk of inadvertent escalation. As a result, both have made frequent positive gestures indicating willingness to improve crisis management (Odell 2021; Detsch 2021). The Biden administration clearly stated that "the US seeks competition with China, but does not look for confrontation" (Biden 2021). During a phone call with Biden, President Xi Jinping pointed out that "the China-US relationship is currently at an important juncture, and while the two sides

Bo $\mathrm{Hu}$

hupoo@pku.edu.cn

1 School of International Studies, Peking University, Beijing, China 
may differ on some issues, it is crucial to show mutual respect, treat each other as equals, and properly manage and handle the differences in a constructive fashion" (Xinhuanet 2021). China has also emphasised on many occasions the importance of "focusing on cooperation and narrowing differences" (Wang 2021). However, the reality is that as both sides seek to show strong determination, crisis management between China and the US has stagnated and even retrogressed, with military competition at sea escalating. ${ }^{1}$ The US has long accused China of showing limited willingness and sincerity toward relevant initiatives from the US. At the same time, China has called American actions confusing and accused the US of misleading public opinion. Beijing holds that Washington should bear full responsibility for America hardline position on aspects such as agenda setting (Liu 2020).

\section{Special features of China-US military competition}

Even without the problems of intentions and misunderstandings, the prospects for finding common ground on crisis management are clearly weak due to the unique nature of China-US military competition. Due to the changes of the times, advancements in military technology, and differences in strategic culture, contemporary China-US military relations feature the following five points, which distinguish it from past great power competitions.

\subsection{Maritime-centered confrontation}

China-US competition mainly occurs at sea, which is different from most cases of great power competition. With its nuclear capability far behind that of the US, China does not constitute a main nuclear competitor to the US. As the two countries do not share land borders and American military forces are not dispatched to the frontier zone of China, the possibility of a direct land-based confrontation is minimal. The prospect of a possible conflict over Taiwan is an exception to this, though maritime and air operations would take precedence over land battles in this case. Unlike previous great power dyads, competition between China and the US mainly takes place at sea rather than on land or in the nuclear realm (Caverley and Dombrowski 2020a). The waters of the western Pacific have become the focal point of a bilateral competition in which the balance of power between the two sides is changing rapidly, possibly approaching a neck-and-neck situation.

Competitions at sea are often unstable due to the absence of fixed boundaries and distinctions between front and rear. With the increased mobility and/or range of sea and land platforms, the scope of competition has been expanded and the types of

\footnotetext{
1 From the Clinton to Obama administrations, China and the United States established almost 20 mechanisms for dialogue and crisis management in the field of military security. These mechanisms were mainly criticized as having low effectiveness. Since the Trump administration, even these inefficient interactions have become less frequent. In 2021, the two militaries did not hold their first formal talks on risk management under the Biden administration until August 27th.
} 
competition have become more complicated. In terms of the offence-defence balance, maritime platforms are flexible by nature, and the distinction between offensive and defensive platforms and weapons is becoming blurred (Blagden et al. 2011). The development of a country's navy and sea power, for whatever reasons, is an expansive move in the eyes of its competitors. Notably, though the practice enhances the country's deterrence capability, it also provokes more conflict. Although a strong defence force is commonly regarded as the most effective deterrent, sea power is a contradictory balance. That is, though developing sea power effectively responds to the threat of war, doing so also increases the risk of friction and conflict (Gartzke and Lindsay 2020). Therefore, we may continue to observe a paradoxical trend: large-scale warfare at sea is relatively rare, while naval confrontation or friction is becoming more frequent.

Security relationships cannot be separated from the assessment of two factors: capabilities and intentions. Arms control deals with the quantifiable technical issue of capabilities, while confidence building addresses the more challenging and subjective matter of intentions (Griffiths 2010). However, both factors are difficult to assess. Because of the mobility and dynamic distribution of maritime forces, as mentioned above, there are few cases of successful arms control of sea power in history. Increasingly complex military systems have rendered the evaluation of mutual capacities almost impossible. Intentions are even more complicated to judge. First, every nation has differing maritime priorities and interests arising from their unique geographies, economies, histories, and political stances. Second, beyond being warfighting organizations like ground armies, navies also hold diplomatic and policing duties to maintain maritime order in peacetime (Griffiths 2010). The current conditions have made the tasks of navies more challenging and complicated.

\subsection{Asymmetric and unbalanced capacities and interests}

Whereas US and Soviet forces had comparable nuclear and military capabilities in the terminal phase of the Cold War, the China-US military balance will remain asymmetric for the foreseeable future. Washington's weaponry, training, and systems integration today remain far ahead of Beijing's, notwithstanding the significant strides the People's Liberation Army has made in recent years. Due to the lack of credible conventional deterrence between China and the US, this asymmetry will lead to instability (Goldstein 2013). Further, the struggle between the US and the Soviet Union was mainly focused in their overseas regions, such as Eastern Europe, Asia, Africa, and Latin America, and one did not usually pose a direct threat to the sovereignty and security of the other except through nuclear deterrent. Nor did either side of the US-Soviet competition feel that their obtained power decided by post-world war II order arrangement was being "taken away" or that what should have belonged to them should be "taken back" (Cossa 2008, 397-398).

China-US competition is primarily confined to the environs of the Chinese mainland, which places China at an obvious strategic disadvantage. Through its close relations with Chinese Taiwan Authorities and the deployment of American forces throughout East Asian waters, the US has long been involved in undermining 
China's national unity, territorial integrity, and maritime rights. In contrast, China is currently far from being capable of projecting military power on a similar scale, i.e., from projecting power to the periphery of the US and intervening in its affairs. Moreover, in comparison with the general tolerance of the balance of power between the US and the Soviet Union in Europe during the Cold War, Beijing and Washington still have not accepted each other's areas of predominance and military presence in East Asian waters, including the East and the South China Seas and the Taiwan Strait (Layne 2020).

As a result, China will not be as open and confident as the US in the process of establishing crisis management mechanisms and negotiations. From the perspective of Beijing, developing a China-US code of conduct for military encounters would be like giving seat belts to speeders, effectively allowing Washington to manage the risks posed by its military operations in the region surrounding China (Campbell and Wyne 2020). Therefore, the two sides attach priority to different subjects during dialogues and negotiations. While China emphasizes national security as well as operational safety, the US mainly focuses on the freedom and safety of its own operations.

\subsection{High transparency in the game environment}

The confidentiality of interactions and centrality of decision-making have long been an enduring and important guarantee for the maintenance and development of the China-US relationship. However, it is now increasingly difficult to maintain these conditions. More entities have started to engage in and influence the decision-making process, adding more debate to each side's policies towards the other. In addition, the strategic and tactical environments of the China-US crisis management game have become more transparent, handicapping bilateral crisis decision-making.

First, the strategic environment is becoming transparent. Broad participation from mass media and the public greatly influence the decision-making of governments around the world. Previously, great power military games were limited to the involvement of both sides' leadership and professional command organs, which had a monopoly on control over the situation and critical information. Even people in military forces mostly took orders without having the whole picture of the situation. In today's world, with increasing access to quality open-source data and global use of social media platforms, the public has more access to and knowledge of political and military information. Relevant issues and actions are openly discussed and are subject to public and international scrutiny. The "quiet diplomacy" approach, while highly successful in handling major emergencies and military crises, is hardly applicable in the current connected world because of this open game environment. The 2001 China-US EP-3 incident would not be resolved the same way if it occurred today, even if all other conditions remained the same, because the transparency of the current strategic environment would inevitably make resolution of the incident more difficult.

Second, the tactical environment is also becoming transparent. The development of persistent intelligence, surveillance, and reconnaissance (ISR) capabilities has 
enabled the provision of more precise, real-time battlefield information during both combat and confrontations. Even for amateurs, the overall state of combat and confrontation situations is not difficult to grasp. These advancements in ISR technologies are leading to a "zero-sum game" dilemma because of transparence in which neither side dares to step back. This dilemma is even more apparent in China-US maritime conflicts and confrontations in which both sides possess powerful situational awareness.

\subsection{Differences in strategic culture}

Jack L. Snyder was the first to give an academic definition to strategic culture, defining it as the sum total of ideals, conditioned emotional responses, and patterns of habitual behavior that members of a national strategic community have acquired through the instruction of imitation (Snyder 1977). The concept focuses on ideas and assumptions that influence national military choices of actions, especially ideas about wars, preference between offense and defence, and acceptance of injuries and deaths (Rosen 1995). In general, strategic culture is defined as a particular security and military vision that influences policymakers. The endurance of such modes of thinking qualifies them as manifestations of a "culture", rather than mere policy (Al-Rodhan 2015). The strategic culture of a state is formed from a comprehensive survey of factors, including geopolitics, customs, historical memories, and political systems.

Due to their distinct geographical environments, historical experiences, and state systems, China and the US demonstrate substantial cultural differences in employing and exercising their armed forces. Previous great power competitions certainly witnessed differences in strategic cultures, but one as significant as the present difference between Chinese and US strategic culture was rarely seen. Since the end of World War II, Washington has employed an offensive policy of national defense, with its defensive perimeter expanding to the whole planet, including the environs of China. In contrast, Bejing sticks to a defensive policy of national defense, focusing its strategic priority on its lands and surrounding areas. This difference leads to distinct emphases in crises: the US prioritizes external influence while China regards territorial sovereignty as its core concern. Comparing actions taken by China and traditional great powers such as the US and Soviet Union in crises, Alastair Iain Johnston concludes that China attaches far greater importance to territorial sovereignty than other countries. He explains that China has formed a unique type of nationalism and anxiety with regard to its political legitimacy due to its experiences as a newly independent country with a 100 years of humiliation (Johnston 2016).

As peace is regarded as most precious in Chinese culture, China tends to be cautious in launching military operations and is not used to engaging in deterrence and matching responses. During crises, Beijing usually resorts to diplomatic approaches such as condemnation, protest, and reasoning. Violence is avoided unless the situation is irretrievable. As Chinese diplomatic statements have lacked corresponding actions, the outside world is often misled and uncertain of China's stance and bottom line. China is not good at taking preventive measures to address conflicts 
and crises before they break out. However, once they have broken out, China takes relatively aggressive reactive measures to avoid further losses. These measures have been negatively interpreted as belligerent and expansionist (Hu 2019). In comparison, as a country long in a state of war since its independence, the US emphasizes deterrence and preventive intervention and has shown a low threshold for using force towards other countries, especially after the Cold War.

Because Chinese culture emphasises stability and the big picture, China usually exercises restraint until a crisis has reached full confrontation or a full-scale war. Its emphasis on stability demonstrates that China has a restrained preference for "reducing major issues to minor ones, and then minor issues to naught". ${ }^{2}$ With regard to big picture considerations, during a crisis, military command at all levels, including frontline troops, consciously obey China's macro plans for diplomacy and national defense while considering micro gains and losses. Further, China pays great attention to right and wrong and the determination of responsibility. When a crisis breaks out, the first Chinese reaction is not to manage the situation but to determine the responsible party. As a result of its concern over responsibility and national dignity, Beijing sometimes pays more attention to symbolic gestures such as public apologies (Wu 2008).

In comparison, Washington is accustomed to seeking military, legal, or technical solutions to specific problems by exchanging benefits and to managing crises by simultaneously using both pressure and inducements from the angle of game theory (Wang and $\mathrm{Xu}$ 2007). The US pays more attention to the incident itself, considering problems from the operational level with a strong utilitarian tendency and emphasizing shaping the situation and maximizing its own national interests (Ding 2004).

Moreover, the two countries have different political and institutional systems and modes of decision-making, with departments varying in authority and responsibility. When a crisis happens, the competent authorities of each side may not be able to find the appropriate counterpart with whom to conduct effective communication and dialogue.

The only common feature shared by Chinese and American strategic culture is that both are unaccustomed to the current balance of power and power equilibrium. This poses an obstacle to strategic interaction between the two countries. China occupied the dominant position in East Asia for an extended period in ancient times. In modern times, it has mostly played the role of either a backward or a major country and has little experience with coexisting with other great powers as a powerful state. In contrast, the US is used to its global dominance, as reflected by its innate arrogance and sense of American exceptionalism. The essential question of this bilateral relationship is this: to what extent can China and the US accept each other's powerful presence and influence?

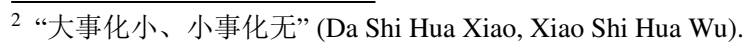




\subsection{Uncertainty caused by new technological developments}

The development of military technology often plays a significant role in promoting or influencing military competition. Offense-defense balance theory elucidates that military technology is the most crucial systematic variable affecting strategic stability. The relative ease of offense and defense is determined primarily by the prevailing state of technology at any given time (Lieber 2000). There appears to be some consensus among scholars and practitioners that mobility innovations favor offense, whereas firepower innovations favor defense (Lieber 2000).

Although no large-scale naval battles among great powers have occurred since the Second World War, many technologies have been developed since then. Some of the newer technologies include nuclear submarines, air defense systems, stealth missiles, and vertical launch systems. The latest innovations, such as cyberweapons, anti-satellite weapons, hypersonic missiles, long-range anti-ship missiles (LRASMs), quantum computing, and artificial intelligence, have greatly compounded uncertainty (Caverley and Dombrowski 2020b; Horowitz 2019). Maritime military systems have become so complex that the boundaries between land, sea, air, space, and cyberspace are now blurred (Schneider 2019). Maritime military competition has become the confrontation in all domains with all the services and arms involved. For the first time in history, maritime military competition spans all services and domains. Therefore, it has become increasingly difficult to evaluate one's own capabilities as well as those of rivals, making it difficult to implement arms control and establish mutual trust.

The application of unmanned systems and autonomous weapons also impairs political and moral restrictions on the utilisation of military force, which may lower the threshold for military conflict. Further, autonomous weapons may also be disturbed by electromagnetism or algorithmic errors, resulting in miscalculation or misoperation. Continued advances in offensive cyber capabilities increase the risk of inadvertent escalation, potentially up to the nuclear level, making the impoverishment of US-China military ties and the deteriorating security environment in the Asia-Pacific even more concerning (Campbell and Wyne 2020). Today, neither China nor the US is confident in its ability to manage conflicts to prevent escalation into nuclear war.

\section{Crisis management under the peaceful coexistence framework}

Based on the above analysis, present China-US crisis management differs from the management and control of great power competition in history. For instance, "[d] uring the Cold War period, research on crisis management among Western countries mainly focuse[d] on preventing the crisis between the US and the Soviet Union from escalating into nuclear conflicts"(Yang 2004, 23). Following the Cold War, bilateral crisis management between China and the United States has focused on eliminating or alleviating the disruptive effects of military competition or crises on overall relations. However, in any case, the advancement of contemporary political culture and transparency has increased restrictions on armed conflicts. Under these 
circumstances, China and the US should adopt more positive guiding principles for crisis management, prioritising the prevention of both countries from engaging in direct military confrontations. In the future, instead of sitting by and waiting for improvement in the overall relationship to facilitate crisis management, China and the US should take more direct measures to prevent the overall relationship from hampering crisis management. Thus, China-US crisis management should be wary in drawing upon historical experience and lessons, which are significant but far from sufficient.

The management of China-US military competition encompasses both strategic and operational issues and thus must be coordinated. The essential questions in terms of strategy are the extent to which China and the US can accept each other's powerful presence and influence and whether both countries can coexist peacefully. The main issue at the operational level is whether the two countries can explore to establish a series of effective maritime and air rules of conduct under different geographical environments, strategic cultures and decision models.

\subsection{Strategically, both parties need to accept the limits of their power}

Crisis management is mainly about strategy: effectively managing a crisis can be perilously tricky if the underlying structure of the geopolitical environment is unstable (Alcazar 2012). Historical experience suggests that each side's strategic perspective of the other plays an essential role in China-US crisis management: "The China-US crisis management is closely associated with the fact whether they are confronted with shared security threats and with the acknowledgement of leaders of both countries on bilateral relations" (Wang and Xu 2007, 44).

With regard to great power competition, it is almost impossible for both parties to find enough shared security threats from third party; instead, they can only try to grasp the limitations and bounds of the competition objectively. Crisis management depends on mutual strategic adaptation and adjustment, and both sides should consciously work to establish a relationship of constrained competition. Specifically, constrained US-China competition requires the US to adjust to the power transition between the two and acknowledge Chinese interest in acquiring greater influence in the western Pacific. On the other hand, it also requires China to acknowledge American security concerns and for Beijing to restrain itself from using its maritime capabilities and to exercise patience to realise a revised regional security order (Ross 2020).

Due to realistic concerns, neither party is likely to exclude the other from the western Pacific or even larger areas, regardless of how the power distribution between China and the US develops in the future. Whether these two countries can find a way to coexist peacefully at sea will influence the future trends of their overall relationship and determine the future international landscape and order. While the rapid rise of China has narrowed the gap between the two countries, it is still impossible for China, regardless of its will, to challenge the US on a global scale in terms of military capability in the foreseeable future. That being said, one must note that the US's dominance in some parts of the Asia-Pacific region is now giving 
way to a balance of power to some extent. The China-US power transition commonly mentioned has taken place mainly in the Asia-Pacific region, especially in East Asia. The US should consider accepting the objective change in the balance of power in East Asian waters. If the US persists in maintaining its hegemonic position and exclusive security order in the region, the nightmare of China-US conflict may become unavoidable. Meanwhile, China should also come to terms with the inevitable fact that the US has a strong presence in the region and will continue to in the long term.

In the western Pacific, the two countries must adapt to the balance of power structure created by the new power distribution while recognising their own weaknesses and accepting each other's strategic vulnerability. They should use their force and power cautiously, hold back from overaggressive behavior, and learn to live together, as "Efforts by the United States or China to secure future predominance will prove futile and dangerous, given a host of security, economic, and diplomatic factors" (Swaine et al. 2016, 1).

Given the strategic reality of mutual tolerance and compromise, strategic selfconsciousness is needed for both countries to strive for success. Efforts should be made as soon as possible to hold dialogues on the regional arrangement in the western Pacific, carry out substantive consultations on each other's strategic visions, and organize arms control dialogues or impose mutual restrictions on maritime armament development. It is crucial for China and the US to reach a consensus on power distribution and the balance of power. An agreement would contribute to establishing a security framework that features inclusiveness and coexistence. To this end, both countries must maintain strategic rationality to surpass previous crisis prevention and management norms. Even if there is no improvement in the strategic and overall relations between China and the US, positive crisis management endeavors are still needed to prevent the situation from spiraling out of control.

Objectively speaking, there is no fierce competition between the two countries in areas outside of the western Pacific. The ascendence of China, especially its maritime rise, largely relies on the openness of the global system. China's sea lines of communication and overseas interests cannot be safeguarded without cooperation with the US and its allies. The main objective of China's open seas protection is to safeguard maritime security rather than to engage in geopolitical competition. It is necessary for China to keep its defensive national defense strategy and reinforce the transparency of the "going out" 3 policy for its armed forces. The US needs to realize the vulnerability of China's maritime strategy and the fact that it is unnecessary and counterproductive to exaggerate or overreact to the threat posed by China. Given the vulnerability of China in vast sea areas across the world, transferring part of its power in the western Pacific to Beijing would not undermine the US's maritime dominance globally.

Considering the lack of mutual strategic trust between China and the US, with both parties holding that the other side is establishing an exclusive maritime order, it is necessary for leaders of both sides to repeatedly proclaim to the public that

3 “走出去” (Zou Chu Qu). 
"we are not pursuing an exclusive regional architecture and are willing to accept the other's powerful military presence in these regions." Of course, they also need actions to prove.

\subsection{Rules of consensus}

In the maritime order of the Asia-Pacific region, both parties have, at least in official rhetoric, stressed the building of a "rules-based international order" or "international law based order". However, they are at odds over what kind of rules and laws should apply. Existing international laws and regulations, including the United Nations Convention on the Law of the Sea (UNCLOS), are vague and have few relevant provisions regarding military security, which are unable to provide clear rules for peacetime military operations at sea and air. Under the circumstance of general peace, both China and the US have no other choice but to seek a series of mutually recognized or shared maritime rules. The most urgent issues involve military operations in exclusive economic zones, air and sea encounters, and unmanned platform activities.

\subsubsection{Military operations in exclusive economic zones}

China and the US differ significantly in their understandings of foreign military operations in territorial waters, contiguous zones, exclusive economic zones, and other sea areas. Among their different understandings, the most consequential divergence lies in the right to deploy military operations within other states' exclusive economic zones. The Chinese side emphasizes the principle of "due regard" as mentioned in Paragraph 3 of Article 58 of UNCLOS, which means that military operations conducted by other countries within an exclusive economic zone should take the coastal state's security and interests into account. The Law on the Exclusive Economic Zone and the Continental Shelf of the People's Republic of China, enacted in 1998, underlines that freedom of navigation and overflight must comply with "international law and the laws and regulations of the People's Republic of China." As for the US, it argues that sea areas beyond 12 nautical miles from the baseline of the coastal state are international waters; the US military has absolute freedom of operation in those areas and coastal states have no right to interfere.

The two sides, along with other supporters of their respective interpretations in the international community, represent two fundamentally different maritime practices. Since the two interpretations are both partially rational, it is meaningless for the two sides to blindly criticize one another. Instead, it is more realistic for them to mutually agree on a negative list for specific operations within other countries' exclusive economic zones. Given the US Navy's unique capacity of power projection across the world, the mismatched military strength between China and the US, the differences in the two sides' national defense strategies, and the fact that the US maintains a robust and regular presence in China's exclusive economic zones while Chinese forces have only conducted occasional operations in the exclusive economic zones of Guam and Hawaii, there is a serious strategic imbalance between China 
and the US. Therefore, this seemingly rules-related issue is actually one that concerns strategy and security. Because China perceives many American operations in its exclusive economic zones as bearing animosity, it opposes them due to sovereignty and security concerns rather than legal reasons.

\subsubsection{Maritime and air encounters}

With rapidly increasing sea and air encounters between China and the US, there is also an urgent need to develop a set of norms for coexistence in the region. The US military is not accustomed to the swift growth of China's maritime power. At the same time, the rising Chinese military lacks experience in dealing with its relationship with the US military. The vast western Pacific is becoming more crowded due to the two forces' ongoing coexistence in the region, and military operations taken against one another will become inevitable. To avoid miscalculation and crisis escalation, it is essential for the two sides to agree upon a set of rules or norms on their military operations, with the rules on maritime and air encounters and the mutual notification mechanism for major military operations being two notable examples of such agreements. Next, the two sides should continue to implement in-depth negotiations and strive to reach a consensus on the bottom-line rules for specific military operations, such as military exercises, reconnaissance, and underwater activities, in the region to eliminate dangerous actions. For instance, if both sides can agree on the details and specifics of minimum safe distance between aircraft/vessels and what constitutes a dangerous maneuver, the risk of accidental conflict will be greatly reduced.

Existing international rules are basically adequate for handling unplanned encounters. Since the International Regulations for Preventing Collisions at Sea 1972, formulated by the International Maritime Organization (IMO), came into force on July 15, 1977, it has served as a globally recognized maritime traffic standard. Both China and the US are member states. According to the Code for Unplanned Encounters at Sea (CUES) adopted in 2014, in the event of unplanned encounters by naval vessels or aircraft of different countries, necessary safety measures and means should be taken to minimize mutual interference and uncertainty and to facilitate communications. CUES defines the legal status, rights, and obligations of naval vessels and aircraft and provides maritime safety procedures, communications procedures, elected signals vocabulary, and basic maneuvering instructions for unplanned encounters at sea. So far, both Chinese and US forces have generally abided by CUES, but certain disputes remain in its scope of application. China insists that CUES does not apply to territorial waters, while the US holds that it does.

Furthermore, the US expects to extend CUES to coast guards (Garamone 2015). This view is not acceptable to China for two reasons. First, the capabilities and operational scopes of each side's coast guard are mismatched. The US Coast Guard is deployed globally, whereas the China Coast Guard mainly operates in China's surrounding sea areas. Second, coast guards and other law enforcement forces are inherently compulsory and confrontational in their rights protection and law enforcement processes in a way that exceeds even military forces in peacetime (Bateman 2016), 
which makes that the rules of CUES shall not apply to the encounters between coast guards or between law enforcement forces.

Regardless, the existing rules are far from adequate for handling intentional encounters. These encounters between the Chinese and US militaries include freedom of navigation operations (FONOPs); close-in reconnaissance operations on China conducted by US forces; tracking, surveillance, and expelling activities conducted by China; and counter-surveillance activities taken by each side against the other. To establish specific rules of conduct based on the "two confidence-building mechanisms", both sides need to further specify or standardize relevant technical details and enhance the binding force of existing rules. These rules should be applicable in areas beyond the 12 nautical mile limit of territorial waters or stationed features, where there is an unbridgeable divide between the two parties: the US accuses China of violating freedom of navigation (FON), whereas China holds that the US impinges on its sovereignty. From Beijing's point of view, US freedom of navigation operations (FONOPs) in its 12 miles waters is not about FON but rather political and military provocation. By exaggerating or distorting China's threat to FON, the US will only provoke further military operations by the two parties and increase the risk of crisis escalation (Swaine et al. 2021).

\subsubsection{Unmanned platforms}

The large-scale development and deployment of unmanned platforms such as unmanned aerial vehicles (UAVs) and unmanned underwater vehicles (UUVs) have greatly increased risks and complexity in China-US military interactions. On December 15, 2016, a UUV operated by the US military was met by the ASR-510, a Chinese naval submarine salvage and rescue ship. Though the incident was well resolved, no disposal practice for the future has been formulated. Moreover, the said UUV was unclassified and non-offensive and was used mainly for submarine topography measuring, reducing the political sensitivity of the incident.

Due to the vigorous development and military application of unmanned technologies and unmanned platforms, the future is becoming increasingly uncertain. As the two most significant powers in unmanned and underwater technology development, it is of vital importance for China and the US to formulate codes of conduct in these two fields. For example, they should clarify whether unmanned maritime systems should enjoy the same status as ships or warships (Schmitt and Goddard 2016) and whether there are any applicable rules in the event of maritime incidents between unmanned and manned platforms. At present, there are few rules on unmanned platforms and underwater activities. As the Biden administration has indicated the need to strengthen arms control against China and Russia in emerging fields, discussions on the military application of unmanned technologies could be positive attempt.

\subsection{Supporting mechanisms}

Similar to how mature and well-developed international mechanisms lay an essential foundation for maintaining international relations, building mechanisms is a 
principal crisis management task that serves the primary purpose of reinforcing the predictability of joint actions. It should be pointed out that the direct objectives of maritime confidence-building measures and crisis management are to build trust and enhance transparency at the operational level rather than settle strategic and political issues. To be more specific, efforts should be made to prevent out-of-control incidents from leading to unwanted political and military crises. In addition, in the event of a intentional encounter, it is essential for each side to send clear signals to the other party or parties and to manage the situation through effective communication mechanisms to bring the situation to the desired conclusion (Griffiths 2010).

Maintaining dialogue and communication is crucial to improve mutual confidence (Macintosh 1996). However, certain "mechanism deficits" exist in China-US crisis management. Most of the mechanisms in this regard are still at the stage of taking confidence-building measures and lack sufficient specific measures for effective prevention and crisis management. It is imperative to improve and supplement existing communication and dialogue mechanisms to attain better efficiency. A set of operational procedures should also be established to avoid unnecessary misunderstandings and prevent conflict escalation.

China-US strategic communication and dialogue mechanisms have evolved considerably since the end of the Cold War and peaked during the Obama administration, during which there were nearly 100 mechanisms for intergovernmental dialogue and over 20 mechanisms for military security. Nonetheless, these mechanisms were seriously challenged under the Trump administration; most were terminated or existed in name only. Currently, the two countries and their militaries are still active to a certain degree in communication and dialogue regarding military security. However, the present arrangements [or existing mechanisms] are inadequate, poorly institutionalized, and vulnerable to the general bilateral atmosphere and international situation. When it comes to maritime security policy and dialogue, the Military Maritime Consultative Agreement (MMCA) remains indispensable despite al.l its problems. In 2020, the failure to hold the annual MMCA conference due to COVID-19 and divergence in agenda setting cast a wide shadow over its efficacy. Considering the current political climate, the two parties should first and foremost join hands to ensure that the mechanism continues to work. The US should give due regard to China's concerns over maritime security, and China should increase its understanding of the US's insistence on FON. It is indeed necessary for the two parties to follow the example of the US and the Soviet Union and negotiate a specific and binding agreement on preventing maritime incidents. Given the imbalance in China-US military relations, it is requisite that the two countries tackle more manageable tasks first. The parties should consider establishing a mechanism for preventing maritime incidents or for maritime security and cooperation on the high seas to improve confidence, deepen consensus, and lay a foundation for mechanisms that address sensitive sea areas, including exclusive economic zones and territorial waters.

There are already many international rules and bilateral agreements for safeguarding communications between the two military's frontline forces. In the case of an incident, it is easy for both parties to conduct emergency communication. There is a hotline between the two presidents as they are also commander-in-chief of the 
armed forces, communication is able to be quickly established between them in the event of crises. At the other levels of the middle line of command; however, there are no institutionalized communication channels, for example, between the fleets, theaters, and joint staff departments of both sides. In the event of a crisis, commanders or commands at all levels of the command chain would quickly be involved, therefore both parties must establish effective communication mechanisms across different levels of officers and commanders.

Amid the backdrop of intensified China-US military competition, the two countries will inevitably experience impeded communications and lack confidencebuilding measures at the strategic level. The establishment of crisis management mechanisms should prioritize the standardization of relevant procedures or operations: "It is easy to keep the existing channels open when the two countries coexist in harmony; however, in case of emergency, the reliability of such channels is often compromised. The will is important, but it also needs institutionalised arrangements to safeguard it" (Zhang et al. 2007, 303). Both sides need to lower their expectations of crisis management mechanisms and realistically assess the functionality of such instruments. The mechanisms are meant to maintain dialogue and engagement and to deliver accurate information and expression of intent through communication rather than solve or improve the structural contradictions between the two militaries.

Of course, great powers engaging in crisis management usually have multiple purposes. Preventing maritime incidents is only one of them; restricting their adversaries at the least cost and ensuring the freedom of their own military operations constitute additional significant considerations. The US and especially China "should stay realistic to define the nature of such agreements, instead of overemphasising their significance in strengthening military mutual confidence and improving state-to-state relations" (Zhang 2017, 49).

\section{Conclusion}

In previous studies of China-US interactions on crisis management, the role of willingness to engage in dialogue is usually overstated (Borger 2021; Haenle 2021). Each party criticizes the other for ineffective crisis management resulting from lack of sincerity. This paper has illustrated that the predicament in China-US maritime crisis management is mostly caused by structural or objective reasons. The above argument is not fatalistic and not for some excuse for inaction, but rather seeks make the seriousness of the situation clearer. The process of crisis management will experience great difficulty despite the willingness shown by both sides. In the context of great power competition, strategic distrust and frequent conflicts have aggravated such difficulties. To this end, it is urgent for the two countries and militaries to strengthen mutual strategic adjustment and adaptation at the strategic, tactical, and operational levels.

The management of China-US military competition encompasses both strategic and operational issues and, thus, must be coordinated. An emphasis on strategic intentions or operational practice will not be sufficient; instead, the two must be discussed jointly. To successfully carry out crisis management, both China and 
the US must switch from improving confidence and removing distrust to managing and controlling competition trends and surpass the efforts made by the US and the Soviet Union in the past. After all, contemporary China-US relations are much more positive compared to US-Soviet relations and can hardly endure the latter's level of frequent and intense military frictions. Consequently, both parties need to manage and control maritime military competition to a level acceptable to the world today and in the future.

\section{Declarations}

Conflict of interest The author declares that he has no conflict of interest.

\section{References}

Alcazar, Vincent. 2012. Crisis management and the anti-access/area denial problem. Strategic Studies Quarterly 6 (4): 42-70.

Al-Rodhan, Nayef. 2015. Strategic culture and pragmatic national interest. Global Policy. https://www. globalpolicyjournal.com/blog/22/07/2015/strategic-culture-and-pragmatic-national-interest. Accessed 27 Sept 2021.

Bateman, Sam. 2016. CUES and coast guards. East Asia Forum. https://www.eastasiaforum.org/2016/10/ 07/cues-and-coast-guards/. Accessed 8 Oct 2021.

Biden, Joseph. 2021. Remarks by President Biden in press conference. The White House. https://www. whitehouse.gov/briefing-room/speeches-remarks/2021/03/25/remarks-by-president-biden-in-pressconference/. Accessed 6 Oct 2021.

Blagden, David W., Jack S. Levy, and William R. Thompson. 2011. Sea powers, continental powers, and balancing theory. International Security 36 (2): 190-202.

Borger, Julian. 2021. Hotlines 'ring out': China's military crisis strategy needs rethink, says Biden Asia chief. The Guardian. May 6, 2021. https:/www.theguardian.com/world/2021/may/06/hotlines-ringout-chinas-military-crisis-strategy-needs-rethink-says-biden-asia-chief-kurt-campbell. Accessed 5 Oct 2021.

Campbell, Kurt M., and Ali Wyne. 2020. The growing risk of inadvertent escalation between Washington and Beijing. Lawfare. https://www.lawfareblog.com/growing-risk-inadvertent-escalation-betweenwashington-and-beijing. Accessed 12 Sept 2021.

Caverley, Jonathan D., and Peter Dombrowski. 2020a. Too important to be left to the admirals: the need to study maritime great-power competition. Security Studies 29 (4): 579-600.

Caverley, Jonathan D., and Peter Dombrowski. 2020b. Cruising for a bruising: maritime competition in an anti-access age. Security Studies 29 (4): 671-700.

Cossa, Ralph A. 2008. Taiwan Strait crisis management: the role of confidence-building measures. American Foreign Policy Interests 30 (6): 397-398.

Detsch, Jack. 2021. Biden looks for defense hotline with China. Foreign Policy. https://foreignpolicy. com/2021/05/10/biden-china-xi-jinping-defense-hotline-pentagon/. Accessed 2 Oct 2021.

Ding, Xiaowen. 2004. Comparison and contrast of the characteristics of handling diplomatic crises by China and the United States. International Studies (Beijing) 104 (6): 55-59.

Garamone, Jim. 2015. U.S. outlines Asia-Pacific maritime security strategy. U.S. Department of Defense. https://www.defense.gov/News/News-Stories/Article/Article/614488/us-outlines-asia-pacific-marit ime-security-strategy/. Accessed 28 Sept 2021.

Gartzke, Erik, and Jon R. Lindsay. 2020. The influence of sea power on politics: domain- and platformspecific attributes of material capabilities. Security Studies 29 (4): 601-636.

Goldstein, Avery. 2013. First things first: the pressing danger of crisis instability in U.S.-China relations. International Security 37 (4): 49-89. 
Griffiths, David. 2010. U.S.-China maritime confidence building paradigms, precedents, and prospects. CSMI Red Books, Study No. 6. https://digital-commons.usnwc.edu/cgi/viewcontent.cgi?article= 1005\&context=cmsi-red-books. Accessed 28 Sept 2021.

Haenle, Paul. 2021. Why the U.S. and Chinese militaries aren't talking much anymore. Carnegie Endowment for International Peace. https://carnegieendowment.org/2021/08/11/why-u.s.-and-chinese-milit aries-aren-t-talking-much-anymore-pub-85123. Accessed 4 Oct 2021.

Horowitz, Michael C. 2019. When speed kills: autonomous weapon systems, deterrence and stability. Journal of Strategic Studies 42 (6): 764-788.

$\mathrm{Hu}$, Bo. 2019. Chinese maritime power in the 21st century. Milton Park: Routledge.

Johnston, Alastair Iain. 2016. The evolution of interstate security crisis-management theory and practice in China. Naval War College Review 69 (1): 28-71.

Layne, Christopher. 2020. Coming storms: the return of great-power war. Foreign Affairs. https://www. foreignaffairs.com/articles/united-states/2020-10-13/coming-storms. Accessed 15 Oct 2021.

Lieber, Keir A. 2000. Grasping the technological peace: the offense-defense balance and international security. International Security 25 (1): 71-104.

Liu, Wensheng[刘文胜]. 2020. Senior Colonel Liu Wensheng, spokesperson of the Chinese Navy, responded when asked about the U.S. accusation on China's refusing to participate in the ChinaUS maritime security meeting (海军新闻发言人刘文胜海军大校就美称中方拒绝参加中美海上 军事安全磋商机制会议答记者问). Ministry of Defense of the People's Republic of China. http:// www.mod.gov.cn/topnews/2020-12/17/content_4875667.htm. Accessed 2 Oct 2021.

Macintosh, James. 1996. Confidence building in the arms control process: a transformation view. Ottawa, Canada: Department of Foreign Affairs and International Trade.

Odell, Rachel Esplin. 2021. How nongovernmental actors can improve crisis management in U.S.-China relations. The Carter Center. https://us-china.report/management/. Accessed 23 Sept 2021.

Rosen, Stephen Peter. 1995. Military effectiveness: why society matters. International Security 19 (4): 5-31.

Ross, Robert S. 2020. It's not a cold war: competition and cooperation in US-China relations. China International Strategy Review 2 (1): 63-72.

Schmitt, Michael N., and David S. Goddard. 2016. International law and the military use of unmanned maritime systems. International Review of the Red Cross 98 (2): 567-592.

Schneider, Jacquelyn. 2019. The capability/vulnerability paradox and military revolutions: implications for computing, cyber, and the onset of war. Journal of Strategic Studies 42 (6): 841-863.

Snyder, Jack. 1977. The Soviet strategic culture: implications for limited nuclear options. RAND. https:// www.rand.org/content/dam/rand/pubs/reports/2005/R2154.pdf. Accessed 3 Oct 2021.

Swaine, Michael D., Wenyan Deng, and Aube Rey Lescure. 2016. Creating a stable Asia: an agenda for a U.S.-China balance of power. Carnegie Endowment for International Peace. https://carnegieen dowment.org/files/CEIP_Swaine_U.S.-Asia_Final.pdf. Accessed 2 Oct 2021.

Swaine, Michael D., Jessica J. Lee, and Rachel Esplin Odell. 2021. Toward an inclusive \& balanced regional order: a new U.S. strategy in East Asia. Quincy Institute for Responsible Statecraft. https:// quincyinst.org/2021/01/11/toward-an-inclusive-balanced-regional-order-a-new-u-s-strategy-in-eastasia/. Accessed 5 June 2021.

Wang, Jisi[王缉思], and Hui Xu[徐辉]. 2007. An comparative analysis of Sino-US crisis behavior (中 美危机行为比较分析). In Case study of China-US security crisis management (对抗.博弯. 合作 中美安全危机管理案例分析), ed. Tuosheng Zhang[张沱生], and Wen Shi[史文], 21-52. Beijing: World Affairs Press.

Wang, Yi[王毅]. 2021. Focus on cooperation and narrow differences: pushing China-US relationship back on the track of healthy and stable development (聚焦合作 管控分歧: 推动中美关系重回健 康稳定发展轨道). Foreign Ministry of the People's Republic of China. https://www.fmprc.gov.cn/ web/wjbzhd/t1871189.shtml. Accessed 21 Aug 2021.

Wu, Xinbo. 2008. Managing crisis and sustaining peace between China and the United States. Peaceworks No. 61. Washington, DC: US Institute of Peace. https://www.usip.org/sites/default/files/201906/pw61_finalapr16.pdf. Accessed 23 June 2021.

Xinhuanet. 2021. Xi speaks with Biden on phone. http://www.xinhuanet.com/politics/leaders/2021-02/ 11/c_1127093231.htm. Accessed 23 June 2021.

Yang, Jiemian [杨洁勉]. 2004. China-US relations in post-Cold War era: theory and practice of crisis management (后冷战时期的中美关系 危机管理的理论和实践). Shanghai: Shanghai People's Press. 
Zhang, Yuan[张愿]. 2017. Interpretation of the US-Soviet incidents at sea agreement in 1972 (1972年美 苏《防止海上事件协定》档案解读——兼论其对中国的启示). Journal of Boundary and Ocean Studies 1: 40-51.

Zhang, Tuosheng[张沱生], et al. 2007. Case study of China-US security crisis management (对抗.博弯. 合作 中美安全危机管理案例分析). Beijing: World Affairs Press. 